\title{
Tumor Necrosis Factor Inhibition and Parkinson Disease
}

\section{A Mendelian Randomization Study}

Xiaoying Kang, MSc, MPH, Alexander Ploner, PhD, Nancy L. Pedersen, PhD, Sara Bandres-Ciga, PhD, Alastair J. Noyce, MRCP, PhD, Karin Wirdefeldt, MD, PhD, and Dylan M. Williams, PhD

Neurology ${ }^{\circledR}$ 2021;96:e1672-e1679. doi:10.1212/WNL.0000000000011630

\section{Abstract}

\section{Objective}

To evaluate the effects of long-term tumor necrosis factor (TNF) inhibition on the risk and age at onset of Parkinson disease (PD), we performed a 2-sample Mendelian randomization study using genome-wide association studies (GWAS) summary statistics.

\section{Methods}

Genetic variants in the vicinity of TNFRSF1A, the gene encoding TNF receptor 1 (TNFR1), were identified as predictive of pharmacologic blockade of TNFR1 signaling by anti-TNF therapy, based on genetic associations with lower circulating C-reactive protein (CRP; GWAS n $=204,402)$. The effects of TNF-TNFR1 inhibition were estimated for PD risk $\left(\mathrm{n}_{\text {cases }} /\right.$ controls $=$ $37,688 / 981,372)$ and age at PD onset $(\mathrm{n}=28,568)$ using GWAS data from the International Parkinson's Disease Genomics Consortium and 23andMe, Inc. To validate variants as proxies of long-term anti-TNF treatment, we also assessed whether variant associations reflected anticipated effects of TNFR1 inhibition on Crohn disease, ulcerative colitis, and multiple sclerosis risk $(\mathrm{n}=38,589-45,975)$.

\section{Results}

TNF-TNFR1 signaling inhibition was not estimated to affect PD risk (odds ratio [OR] per 10\% lower circulating $\mathrm{CRP}=0.99 ; 95 \%$ confidence interval $[\mathrm{CI}] 0.91-1.08)$ or age at onset $(0.13$ years later onset; $95 \% \mathrm{CI}-0.66$ to 0.92 ). In contrast, genetically indexed TNF-TNFR1 signaling blockade predicted reduced risk of Crohn disease (OR 0.75; 95\% CI 0.65-0.86) and ulcerative colitis (OR 0.84; 95\% CI 0.74-0.97) and increased multiple sclerosis risk (OR 1.57; 95\% CI 1.36-1.81). Findings were consistent across models using different genetic instruments and Mendelian randomization estimators.

\section{Conclusions}

Our findings do not imply that TNF-TNFR1 signaling inhibition will prevent or delay PD onset.

\section{Classification of Evidence}

This study provides Class II evidence that TNF-TNFR1 signaling inhibition is not associated with the risk or age at onset of PD.

\author{
Correspondence \\ Dr. Williams \\ dylan.williams@ucl.ac.uk
}

\section{MORE ONLINE}

$\rightarrow$ Class of Evidence

Criteria for rating

therapeutic and diagnostic studies

NPub.org/coe 


\section{Glossary}

CHARGE $=$ Cohorts for Heart and Aging Research in Genomic Epidemiology; CI $=$ confidence interval; CRP $=$ C-reactive protein; GWAS = genome-wide association studies; IBD = inflammatory bowel disease; IPDGC = International Parkinson's Disease Genomics Consortium; IVW = inverse variance weighting; LD = linkage disequilibrium; MPV = mean platelet volume; OR = odds ratio; $\mathbf{P D}=$ Parkinson disease; $\mathbf{S N P}=$ single nucleotide polymorphism; $\mathbf{T N F}=$ tumor necrosis factor; $\mathrm{TNFR1}=$ tumor necrosis factor receptor 1 ; WBC $=$ white blood cell count.

Inflammation in the periphery is hypothesized to contribute to the pathogenesis of Parkinson disease (PD), particularly when present in the gastrointestinal tract. ${ }^{1}$ Tumor necrosis factor (TNF) is a potent proinflammatory cytokine that exerts a variety of biological effects by binding to its 2 receptors, triggering intracellular signaling. ${ }^{2}$ Several types of TNF inhibitor have been licensed for the treatment of systemic inflammatory disorders, including inflammatory bowel disease (IBD). ${ }^{3}$ In a recent large cohort study of patients with IBD, exposure to antiTNF therapeutics was associated with lower PD risk, implying that TNF inhibition may be neuroprotective for PD. ${ }^{4}$ However, these findings were observational, and hence prone to several forms of bias that preclude a causal interpretation, including confounding and reverse causation. Moreover, results obtained from a sample of patients with IBD may not be generalizable to individuals without IBD.

Mendelian randomization is a valuable approach to help answer questions in pharmacoepidemiology. ${ }^{5}$ In Mendelian randomization studies relating to pharmacologic exposures, genetic variants that perturb the expression or function of a drug's target (often a specific protein) are used to anticipate the effects of modulating this target with therapeutic use. ${ }^{6}$ Due to Mendelian randomization principles, associations of this genetic variation with diseases are not expected to have arisen from confounding or reverse causation, thus aiding causal inference. ${ }^{7}$ In this study, we used a Mendelian randomization design to further evaluate the therapeutic potential of targeting TNF signaling for PD prevention or treatment, leveraging genetic variation in or near the gene encoding TNF receptor 1 (TNFR1) that is indicative of the blockade of proinflammatory TNF signaling via this receptor. ${ }^{2}$

\section{Methods}

\section{Study Overview}

This study used a 2-sample Mendelian randomization design (figure 1$){ }^{8}$ We focused on single nucleotide polymorphisms (SNPs) in the vicinity of the gene TNFRSF1A, which encodes TNFR1, the principal effector of proinflammatory signaling following TNF agonism. ${ }^{2}$ We determined the extent to which genetic variation in this gene region is indicative of long-term TNF signaling blockade, based on associations of the regional SNPs with circulating markers of systemic inflammation reported by large genome-wide association studies (GWAS) of C-reactive protein (CRP) and cell count measures. ${ }^{9,10} \mathrm{We}$ then combined data on selected variants with corresponding association statistics from GWAS of PD traits to test the effects of TNF-TNFR1 signaling inhibition on (1) the risk of $\mathrm{PD}$, measured as self-reported or clinically ascertained disease status; and (2) age at PD onset, measured as self-reported age at motor symptoms manifestation, or age at PD diagnosis when the former was unavailable. ${ }^{11,12}$ This study provides Class II evidence that TNF-TNFR1 signaling inhibition is not associated with PD risk or age at onset, according to criteria of the American Academy of Neurology.

\section{Indexing TNF Inhibition}

TNF signaling occurs through the binding of the cytokine to its 2 receptors, TNFR1 and TNFR2. We focused on indexing TNFTNFR1 signaling specifically because agonism of TNFR1 mediates the proapoptotic and inflammatory effects of TNF (and hence the efficacy of anti-TNF therapeutics in the treatment of autoimmune diseases), whereas TNFR2 signaling contributes to tissue repair and neuron survival. ${ }^{2,13,14}$ Therefore, researchers have investigated the development of novel therapeutics to selectively antagonize TNFR1 without inhibiting TNFR2-mediated signaling. ${ }^{15,16}$ An effective response to anti-TNF treatment leads to lower systemic inflammation, reflected by reductions in circulating inflammatory biomarkers, such as CRP. ${ }^{17}$ Thus, to validate whether SNPs in the vicinity of TNFRSF1A index the modulation of proinflammatory TNF-TNFR1 signaling, we extracted data on associations of these variants with circulating $\mathrm{CRP}$ from a large GWAS meta-analysis $(n=204,402$; table 1$) .9$ To ensure that the CRP associations were not chance findings, we also examined associations of the SNPs with 2 cell count markers of inflammation - white blood cell count (WBC) and mean platelet volume (MPV) — from independent GWAS data (table 1). ${ }^{10,18}$

In total, 23 SNPs were selected solely from within the gene's genomic coordinates and a narrow flank in either direction (chromosome 12; base pairs 6,437,923-6,451,280 $\pm 1 \mathrm{~kb}$ as per GRCh37 assembly). The choice of a narrow flanking region was adopted to minimize the possibility that the selected variants might associate with PD traits via pathways other than TNFTNFR1 signaling, given that TNFRSF1A is located close to genes that encode other proteins with known immune-related roles, such as lymphotoxin $\beta$ receptor gene LTBR (chromosome 12; base pairs 6,484,534-6,500,737 as per GRCh37 assembly).

\section{PD Data}

Genetic association data for PD risk were derived from a metaanalysis of 16 case-control samples from the International Parkinson's Disease Genomics Consortium (IPDGC) and 23andMe, using the same protocol as adopted in a recent GWAS. ${ }^{11}$ This 
yielded a sample of 37,688 cases and 981,372 controls. Genetic association data for age at PD onset were based on a GWAS comprising 28,568 PD cases from a subset of the cases sampled by the IPDGC and 23andMe, in which the mean age at onset was 61.7 years (range 20-97). ${ }^{12}$ These samples are described further in table 1.

In 2-sample Mendelian randomization, participant overlap between the SNP exposure and SNP outcome samples may bias findings. ${ }^{19}$ However, sample overlap is likely to be nominal in this study because the exposure and outcome GWAS were conducted with largely independent samples: samples for CRP and cell count GWAS were derived primarily from population-based cohorts assembled by the Cohorts for Heart and Aging Research in Genomic Epidemiology (CHARGE) consortium, ${ }^{9}$ and PD GWAS samples were derived mainly from independent case-control studies assembled by the IPDGC and the 23andMe user base (table 1). ${ }^{11}$

\section{Positive Control Analyses}

To validate our study design, we conducted positive control analyses using risk of Crohn disease, ulcerative colitis, and multiple sclerosis as additional outcome traits in our Mendelian randomization models. Protective effects of variants indexing TNF-TNFR1 signaling inhibition were expected for Crohn disease and ulcerative colitis risk because anti-TNF therapies have been approved for treating the 2 conditions. ${ }^{20}$ We anticipated a detrimental effect of variants indexing TNFTNFR1 signaling inhibition on multiple sclerosis, given that the risk of multiple sclerosis is increased by anti-TNF treatment among patients with other autoimmune conditions, and symptom exacerbation has been reported by trials of antiTNF therapies as treatments for multiple sclerosis. ${ }^{21-26}$ For analyses of these positive control outcomes, we used publicly available GWAS summary statistics with overall sample sizes ranging from 38,589 to 45,975 (table 1 ). ${ }^{27,28}$

\section{Statistics}

Prior to statistical analyses, summary statistics for the associations of TNFRSF1A variants with CRP and outcomes were harmonized by aligning the coding of association statistics to the same reference allele (table 2). SNPs were excluded if these were not present in both CRP and outcome datasets, or where the coding of SNPs was ambiguous (palindromic SNPs with minor allele frequencies over 0.4 ).

We conducted Mendelian randomization models based on 3 approaches. In the primary analysis, we applied conservative linkage disequilibrium (LD) clumping $\left(r^{2}<0.001\right)$ to the set of SNPs in the region with CRP association $p$ values under 0.05 , to select independent SNPs with the strongest evidence for association with systemic inflammation. Mendelian randomization results based on this selection criterion were then obtained using Wald estimation, given that a single SNP (rs767455) was retained for analyses. Mendelian randomization estimates can be biased when the genetic variants used in analysis are weak instruments for the exposure being indexed. $^{29}$ Thus, to indicate the strength of this SNP as an instrumental variable, the $F$ statistic for its association with CRP was estimated from the $F$ distribution based on the $p$ value and sample size of SNP_CRP association, with 1 degree of freedom.

Figure 1 Overview of the Study Design

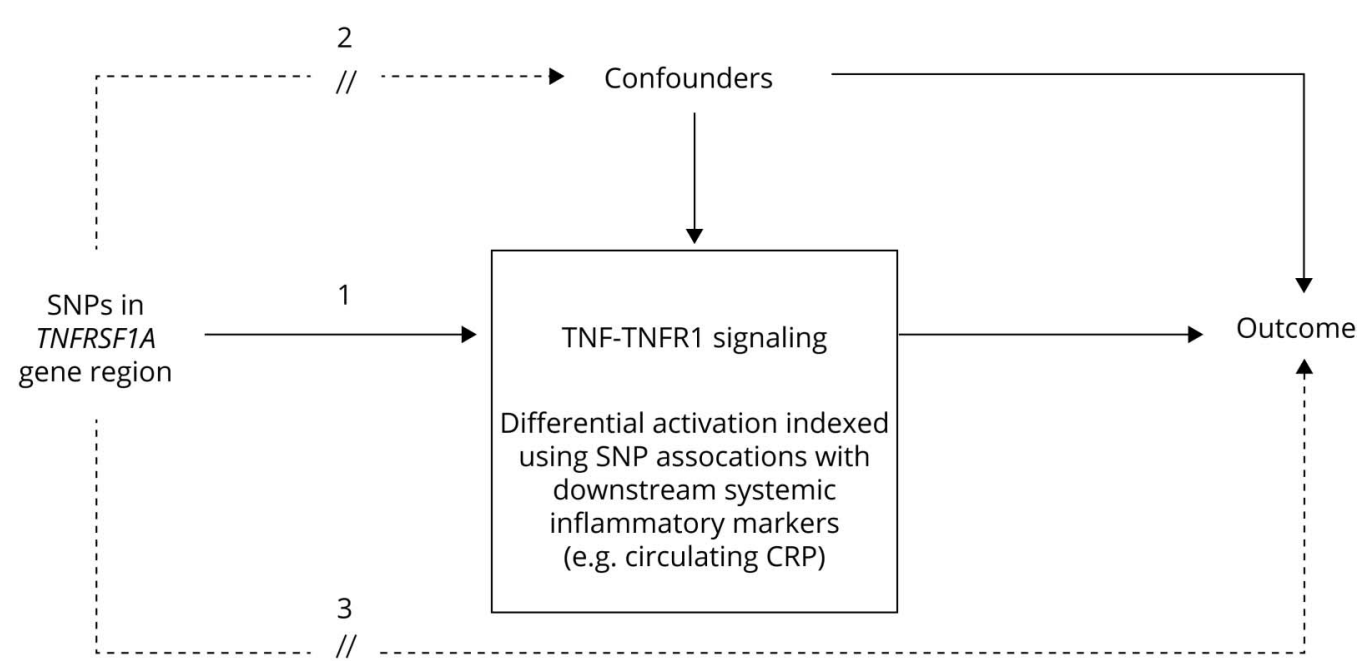

By using only cis-acting variants in TNFRSF1A, the gene encoding tumor necrosis factor (TNF) receptor 1 (TNFR1), and modeling genetic associations with circulating inflammatory markers, the selected genetic instruments are expected to index the overall (averaged) long-term effect of blocking TNF-TNFR1 signaling on Parkinson disease and positive control outcomes (denoted by pathway 1). This is analogous to the pharmacologic modulation of TNF-TNFR1 signaling by TNF inhibitors in vivo (one effect of such an administration being a reduction in systemic inflammation). However, whereas observational studies of associations between TNF inhibitor use and outcomes may be confounded, we do not expect genetic variants within the gene region to be associated with confounders due to the random assignment of alleles at conception (i.e., pathway 2 should not be present). Moreover, variants in a specific gene region are likely to affect outcomes only through effects on the function or expression of the protein encoded by the gene, and hence variants should not be related to outcomes by other routes (pathway 3 ), which would bias our results. CRP = C-reactive protein; SNP = single nucleotide polymorphism. 
Table 1 Summary of the Genome-Wide Association Studies (GWAS) Data Sources

\begin{tabular}{|c|c|c|c|}
\hline Trait & $\begin{array}{l}\text { Sample } \\
\text { size }^{\mathrm{a}}\end{array}$ & Measurement & Reference \\
\hline \multicolumn{4}{|l|}{$\begin{array}{l}\text { Parkinson } \\
\text { disease-related traits }\end{array}$} \\
\hline Risk of onset & $\begin{array}{l}37,688 / \\
981,372\end{array}$ & Self-reported or clinically ascertained & 11 \\
\hline Age at onset & 28,568 & $\begin{array}{l}\text { Self-reported age at initial manifestation of motor } \\
\text { symptoms or age at diagnosis when the former was not available }\end{array}$ & 12 \\
\hline \multicolumn{4}{|l|}{ Inflammatory diseases } \\
\hline Crohn disease & $\begin{array}{l}12,194 / \\
28,072\end{array}$ & Clinically ascertained & 27 \\
\hline Ulcerative colitis & $\begin{array}{l}12,366 / \\
33,609\end{array}$ & Clinically ascertained & 27 \\
\hline Multiple sclerosis & $\begin{array}{l}14,498 / \\
24,091\end{array}$ & Clinically ascertained & 28 \\
\hline \multicolumn{4}{|l|}{$\begin{array}{l}\text { Circulating } \\
\text { inflammatory } \\
\text { biomarkers }\end{array}$} \\
\hline C-reactive protein & 204,402 & Measured by immune assay techniques as $\mathrm{mg} / \mathrm{L}$ and natural log transformed for linear regression & 9 \\
\hline $\begin{array}{l}\text { White blood cell } \\
\text { count }\end{array}$ & 173,480 & $\begin{array}{l}\text { Measured by standard clinical full blood count analysis as aggregate count of white cells per } \mathrm{mL} \text { of } \\
\text { blood, followed by adjustment for technical, environmental, and sex effects }\end{array}$ & 10 \\
\hline Mean platelet volume & 173,480 & $\begin{array}{l}\text { Derived from platelet count (PLT, measured as platelet count per } \mathrm{mL} \text { of blood) and platelet crit } \\
\text { (PCT, measured as volume fraction of blood occupied by platelets) as (PCT/PLT) } \times 10,000\end{array}$ & 10 \\
\hline
\end{tabular}

All samples included participants of European ancestry only.

a Sample sizes represent the entire cohorts for GWAS of age at Parkinson disease onset, C-reactive protein, white blood cell count, and mean platelet volume; and numbers of cases/controls for GWAS of Parkinson disease risk, Crohn disease, ulcerative colitis, and multiple sclerosis.

For secondary analyses, we aimed to retain more variantswhich may explain more variance in CRP and therefore potentially improve the power of Mendelian randomization models-by including all regional SNPs after liberal LD clumping $\left(r^{2}<0.8\right)$. The clumped SNPs were then filtered by requiring false discovery rate-corrected CRP associations with $p$ values under 0.05 , and further associations of the variants with both WBC and MPV (using an unadjusted $p$ threshold $<0.05$ ), ensuring consistent and robust associations of variants with inflammatory signaling were retained. Next, Mendelian randomization estimates based on the set of retained SNPs were calculated using an extension to the inverse variance weighting (IVW) method with principal components to account for the residual correlations between selected SNPs. ${ }^{30}$ This method relies on reference data to adjust for estimated correlations between the SNPs, for which we used data on 502 individuals of European ancestry of the 1000 Genomes project, phase $3 .{ }^{31}$ Principal components explaining over $99 \%$ of variance in the weighted correlation matrix were used in the IVW estimator.

Third, after examining the functional annotation of SNPs in the gene region, we also assessed specific associations of a single SNP (rs1800693) with traits, since this SNP is suggested to affect alternative splicing of the TNFRSF1A transcript to create a soluble TNFR1 isoform, which acts similarly to anti-TNF therapeutics. ${ }^{32}$ In this application, we evaluated genotype-trait associations for the functional SNP rs1800693i.e., not weighted by CRP difference- and results were expressed per copy of the CRP-lowering allele (denoted in the Results as "TNF-inhibiting allele").

All Mendelian randomization outputs were scaled to be expressed per $10 \%$ reduction in circulating CRP, indicative of the direction of effect anticipated from TNF inhibition. ${ }^{33}$ In plots, outputs from logistic regression models were presented as log-odds to scale appropriately alongside $\beta$ s from linear regression models. Corresponding odds ratios (ORs) and 95\% confidence intervals (CIs) for binary outcomes are reported in the Results. Given that we had strong priors for non-null results from positive control analyses, we did not adjust these results for multiple testing correction.

All analyses were performed in R version 3.6.1 (2019-07-05) using TwoSampleMR and mendelianRandomization packages. ${ }^{31,34}$

\section{Standard Protocol Approvals, Registrations, and Patient Consents}

For each GWAS study included in the present work, written informed consent was obtained from all participants and the studies were approved by relevant ethics review boards. Because our study was based on existing summary-level genetic 
Table 2 Descriptive Information on the TNFRSF1A Variants Analyzed in the Study, and Their Associations With Inflammatory Markers and Clinical Traits

\begin{tabular}{|c|c|c|c|c|}
\hline & rs767455 & rs4149570 & rs4149577 & rs1800693 \\
\hline EA/NEA & $\mathrm{T} / \mathrm{C}$ & $\mathrm{A} / \mathrm{C}$ & $A / G$ & $\mathrm{~T} / \mathrm{C}$ \\
\hline Frequency of $E A^{a}$ & 0.57 & 0.40 & 0.52 & 0.59 \\
\hline \multicolumn{5}{|c|}{$\begin{array}{l}\text { Associations with inflammatory marker, } \beta \text { (SE), } p \\
\text { value }\end{array}$} \\
\hline C-reactive protein & $0.023(0.004), 7.8 \mathrm{e}-08$ & $0.016(0.004), 2.4 \mathrm{e}-04$ & $\begin{array}{l}-0.018(0.004), 2.51 \mathrm{e}- \\
05\end{array}$ & $0.024(0.004), 9.2 \mathrm{e}-08$ \\
\hline White blood cell count & $0.011(0.004), 4.2 \mathrm{e}-03$ & $0.015(0.004), 1.3 \mathrm{e}-04$ & $\begin{array}{l}-0.015(0.004), 3.17 \mathrm{e}- \\
05\end{array}$ & $0.010(0.004), 9.1 \mathrm{e}-03$ \\
\hline Mean platelet volume & $0.017(0.004), 3.7 \mathrm{e}-06$ & 0.013 (0.004), 3.6e-04 & $\begin{array}{l}-0.011(0.004), 2.42 \mathrm{e}- \\
03\end{array}$ & $0.016(0.004), 1.3 e-05$ \\
\hline
\end{tabular}

Associations with outcome traits, $\beta$ (SE), $p$ value

\begin{tabular}{lllll}
\hline PD risk & $0.001(0.010), 0.91$ & $-0.003(0.011), 0.78$ & $-0.002(0.01), 0.86$ & $0.002(0.010), 0.84$ \\
\hline PD age at onset & $-0.030(0.093), 0.75$ & $-0.015(0.098), 0.88$ & $0.019(0.093), 0.84$ & $-0.055(0.094), 0.56$ \\
\hline Crohn disease & $0.067(0.017), 5.9 \mathrm{e}-05$ & $0.054(0.017), 1.4 \mathrm{e}-03$ & $\begin{array}{l}-0.046(0.016), 5.39 \mathrm{e}- \\
03\end{array}$ & $0.058(0.017), 5.4 \mathrm{e}-04$ \\
& & & \\
\hline Ulcerative colitis & $0.039(0.016), 0.02$ & $0.033(0.017), 0.05$ & $\begin{array}{l}-0.036(0.016), 2.57 \mathrm{e}- \\
02\end{array}$ & $0.032(0.016), 0.05$ \\
\hline Multiple sclerosis & $-0.104(0.017), 3.30 \mathrm{e}-$ & $\begin{array}{l}-0.078(0.019), 5.51 \mathrm{e}- \\
05\end{array}$ & $\begin{array}{l}0.093(0.017), 5.19 \mathrm{e}- \\
08\end{array}$ & $-0.135(0.017), 6.92 \mathrm{e}-$ \\
& 10 & & 16
\end{tabular}

Abbreviations: $\mathrm{EA}=$ effect allele; NEA = noneffect allele; $\mathrm{PD}=$ Parkinson disease.

a Based on allele frequency reported by the genome-wide association studies on PD risk analyzed in this study. Single nucleotide polymorphisms were labeled with respect to GRCh37 reference coordinates.

results-i.e., without accessing individual-level genetic data—no additional ethical approval was required.

\section{Data Availability}

The majority of genetic association statistics used in this study are presented in table 2. Full CRP GWAS summary statistics can be obtained by contacting the corresponding authors for the CHARGE Inflammation Working Group. Summary statistics from GWAS of WBC and MPV are publicly available at bloodcellgenetics.org $/ .{ }^{35}$ Full PD GWAS data can be obtained via research project applications to $23 \mathrm{andMe}$, Inc. and the IPDGC.

Figure 2 Estimated Effects of Tumor Necrosis Factor (TNF)-TNF Receptor 1 (TNFR1) Inhibition on Outcomes From Mendelian Randomization Models Using Single Nucleotide Polymorphism rs767455 as a Genetic Instrument

Outcome

$\mathrm{N}$

$37,688 / 981,372$

Risk

28,568

Inflammatory diseases

Crohn

UC

MS
$12,194 / 28,072$

$12,366 / 33,609$

$14,498 / 24,091$
Inhibition protective Inhibition detrimental Beta

$95 \% \mathrm{Cl}$

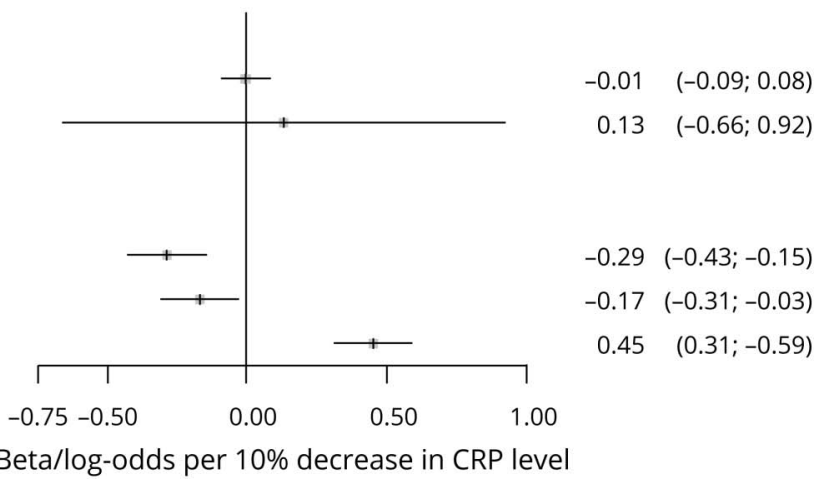

$\mathrm{AAO}=$ age at onset; $\mathrm{Cl}$ = confidence interval; Crohn = Crohn disease; $\mathrm{CRP}=\mathrm{C}$-reactive protein; $\mathrm{MS}=$ multiple sclerosis; $\mathrm{UC}=$ ulcerative colitis. 
Table 3 Mendelian Randomization Estimates for Effects of Tumor Necrosis Factor-Tumor Necrosis Factor Receptor 1 Inhibition on Outcomes Using Multiple Variants as Instruments

\begin{tabular}{lll}
\hline Outcome & OR/ $\boldsymbol{\beta}(95 \% \mathrm{Cl})^{\mathbf{a}}$ & $\boldsymbol{p}$ Value \\
\hline PD risk & $0.99(0.91$ to 1.08$)$ & 0.86 \\
\hline PD age at onset & $0.14(-0.66$ to 0.93$)$ & 0.74 \\
\hline Crohn disease risk & $0.75(0.65$ to 0.87$)$ & $8.30 \mathrm{e}-05$ \\
\hline Ulcerative colitis risk & $0.85(0.74$ to 0.97$)$ & 0.02 \\
\hline Multiple sclerosis risk & $1.56(1.36$ to 1.79$)$ & $4.35 \mathrm{e}-10$ \\
\hline
\end{tabular}

Abbreviations: $\mathrm{Cl}=$ confidence interval; $\mathrm{CRP}=\mathrm{C}$-reactive protein; $\mathrm{OR}=$ odds ratio; $\mathrm{PD}=$ Parkinson disease; SNP = single nucleotide polymorphism.

All analyses in this table were based on Mendelian randomization models of 2 principal components derived from the genetic associations of 3 correlated SNPs (rs767455, rs4149570, and rs4149577) with CRP and the outcomes.

${ }^{a}$ Results where risk of diseases (PD and positive control outcomes) are expressed as ORs per a long-term 10\% reduction in CRP, whereas the result for PD age at onset is expressed as difference in years per a long-term 10\% reduction in CRP.

\section{Results}

A total of 23 SNPs in the vicinity of TNFRSF1A were present in the CRP data. One SNP in the region-rs767455-was retained following conservative LD clumping (table 2). This exonic, synonymous SNP has a minor allele frequency of approximately 0.4 and had the strongest evidence for association with CRP of SNPs in the region $\left(p=7.8 \times 10^{-8}\right)$. It is in high $L D$ with the presumed functional variant ( $r$ 1800693) in this region $\left(r^{2}=0.84\right)^{32}$ and the variant is also associated with circulating $\operatorname{WBC}\left(p=4.2 \times 10^{-3}\right)$ and $\operatorname{MPV}\left(p=3.7 \times 10^{-6}\right)$, with consistent directions for all 3 inflammatory markers. Using this variant in Mendelian randomization models, no effects of TNF-TNFR1 inhibition on PD risk (OR 0.99 per $10 \%$ reduction in circulating CRP; $95 \%$ CI $0.91-1.08)$ or age at onset ( 0.13 years of increase; $95 \% \mathrm{CI}-0.66$ to 0.92 ) were predicted (figure 2). In contrast, genetically indexed inhibition of TNF-TNFR1 signaling was predicted to reduce the risk of Crohn disease (OR 0.75; 95\% CI 0.65-0.86) and ulcerative colitis (OR 0.84; 95\% CI 0.74-0.97) and increase the risk of multiple sclerosis (OR 1.57; 95\% CI 1.36-1.81), as expected. The estimated $F$ statistic for the association of rs767455 with CRP was 28.9, suggesting that these Mendelian randomization models were unlikely to have been affected by weak instrument bias (values of $F$ under 10 are of concern).

In secondary analyses, the more liberal LD clumping yielded 4 correlated SNPs associated with CRP at false discovery ratecorrected $p<0.05$. Among these 4 SNPs, one was not associated with either WBC $(p=0.7)$ or MPV $(p=0.95)$ and was therefore removed, leaving 3 variants that were associated with all 3 inflammatory markers for secondary Mendelian randomization models (table 2). Mendelian randomization estimates based on the 3 SNPs, using adapted IVW methodology to account for correlations between the variants, were consistent with the main results: neither PD risk (OR 0.99; 95\% CI 0.91-1.08) nor age at onset ( 0.14 years of increase; $95 \% \mathrm{CI}-0.66$ to 0.93 ) were predicted to be affected by TNF-TNFR1 blockade, whereas anticipated effects on other inflammatory diseases were observed (table 3). Similarly, no associations of the genotypes of

Figure 3 Associations of rs1800693 Genotype With Various Traits

\begin{tabular}{|c|c|c|c|c|c|}
\hline Outcome & $\mathbf{N}$ & Inhibition protective & Inhibition detrimental & Beta & $95 \% \mathrm{Cl}$ \\
\hline \multicolumn{6}{|c|}{ Parkinson disease } \\
\hline Risk & $37,688 / 981,372$ & 1 & - & -0.00 & $(-0.02 ; 0.02)$ \\
\hline AAO & 28,568 & & & 0.05 & $(-0.13 ; 0.24)$ \\
\hline \multicolumn{6}{|c|}{ Inflammatory diseases } \\
\hline Crohn & $12,194 / 28,072$ & $\longrightarrow$ & & -0.06 & $(-0.09 ;-0.02)$ \\
\hline UC & $12,366 / 33,609$ & $\longrightarrow$ & & -0.03 & $(-0.06 ; 0.00)$ \\
\hline MS & $14,498 / 24,091$ & & $\longrightarrow$ & 0.13 & $(0.10 ; 0.17)$ \\
\hline \multicolumn{6}{|c|}{ Inflammatory biomarkers } \\
\hline CRP & 204,402 & + & & -0.02 & $(-0.03 ;-0.01)$ \\
\hline WBC & 173,480 & + & & -0.01 & $(-0.02 ; 0.00)$ \\
\hline MPV & 173,480 & + & & 0.02 & $(0.02 ;-0.01)$ \\
\hline & & $\Gamma 1$ & 1 & & \\
\hline & & -0.15 & 0.10 & & \\
\hline
\end{tabular}

Differences in traits are per copy of tumor necrosis factor (TNF)-inhibiting allele, i.e., the allele associated with lower circulating C-reactive protein (CRP). AAO = age at onset; $\mathrm{Cl}=$ confidence interval; Crohn = Crohn disease; MPV = mean platelet volume; $\mathrm{MS}=$ multiple sclerosis; $\mathrm{UC}=$ ulcerative colitis; WBC = white blood cell count. 
implicated functional variant (rs1800693) with PD risk (OR 1.00 per TNF-inhibiting allele; 95\% CI 0.98-1.02) or age at onset ( 0.05 years of increase per TNF-inhibiting allele; $95 \% \mathrm{CI}$ -0.13 to 0.24 ) were observed, despite strong associations of this SNP with other inflammatory traits (figure 3 ).

\section{Discussion}

To our knowledge, this is the first Mendelian randomization study to address whether exposure to TNF inhibitors affects PD. Leveraging large genetic data on PD risk and age at PD onset, we found no evidence for the potential of TNF-TNFR1 signaling inhibition to prevent or delay PD onset in the general population.

By comparing patients with IBD with and without anti-TNF treatment in a cohort study, Peter et al. ${ }^{4}$ reported that exposure to TNF inhibitors was associated with a $78 \%$ decrease in PD risk (incidence rate ratio $0.22 ; 95 \%$ CI 0.05, 0.88). Although we showed no support for the potential of blocking TNFTNFR1 signaling to lower PD risk, the results should be interpreted carefully in comparison to the observational study for several reasons. First, the 4 TNF inhibitors investigated by Peter et al. $^{4}$ - adalimumab, certolizumab, golimumab, and infliximab-all directly neutralize soluble or transmembrane TNF and disrupt both the TNFR1- and TNFR2-mediated pathways as well as other potential biological effects induced by TNF by any other pathways, ${ }^{4,20,36}$ whereas our results are specific to the selective inhibition of TNF-TNFR1 signaling transduction. However, we note that TNF-TNFR1 signaling is proposed as the major TNF-related neurotoxic pathway to intervene on for PD therapy. ${ }^{14-16,37}$ Second, given that IBD is rare, our findings are more relevant for the general population. The models test whether TNF-TNFR1 signaling blockade affects PD onset regardless of whether or not individuals have a background of severe systemic inflammation. ${ }^{38}$ Consequently, we do not exclude therapeutic benefits in individuals with certain underlying conditions, such as IBD. Third, Mendelian randomization estimates relate to an averaged effect of long-term exposure to the TNF-TNFR1 inhibitors across the life course; therefore, a null result may reflect either a true lack of an overall effect on PD risk at any stage of life or a sum of opposing, period-specific effects that balance out in our models. This scenario might be possible if, for instance, TNF-TNFR1 signaling inhibition is beneficial for PD in older age due to anti-inflammatory effects, but detrimental earlier in life for other reasons (e.g., increased susceptibility to infections or reduced neurodevelopment). Mendelian randomization estimates are also averaged across any tissue-specific effects, whereas therapeutic administration of TNF inhibitors may be limited to effects induced in the periphery. Fourth, because the 4 TNF inhibitors examined by Peter et al. ${ }^{4}$ are large molecules that do not cross the blood-brain barrier (when intact), they are assumed to mitigate peripheral inflammation principally, unless IBD has affected the integrity of the blood-brain barrier to allow TNF inhibitors to act in the cerebral parenchyma. However, the possibilities of opposing period- or tissue-specific effects of TNF inhibition on PD risk are speculative.
In addition to the risk of PD, we also considered whether TNFTNFR1 signaling inhibition may affect the age at PD onset for its relevance to the course of disease progression in lieu of large GWAS of longitudinally measured PD progression, which are not currently available. For a progressive disease such as PD, an exposure affecting the age at onset could do so by either delaying the pathogenesis of PD (i.e., the disease is triggered later) or modifying the rate of $\mathrm{PD}$ progression once the disease process has commenced. In the present study, the long-term blockade of TNF-TNFR1 signaling did not affect the age at PD onset, implying limited potential for TNF inhibitors to affect PD progression (while keeping the aforementioned caveats about interpreting genetic vs pharmacologic results in mind).

The strengths of our study include the use of large-scale genetic data in a Mendelian randomization design to facilitate causal inference, robust metrics for the Mendelian randomization analyses (e.g., satisfactory instrument strength and functional relevance of the genetic variation), and positive control analyses that indicate the validity of using the chosen genetic variants to predict therapeutic effects. This study's main limitations are that we could not examine whether there is an interaction between inflammatory status and TNF inhibition on PD risk or index the effects of TNF inhibition on direct measures of PD progression.

In conclusion, our findings do not support the notion that longterm blockade of TNF-TNFR1 signaling will prevent or delay PD onset. Human genetics provides valuable guidance for therapeutic programs because the chances of successful drug development are substantially improved when genetic evidence links a drug's target to an indication for therapeutic use. ${ }^{39}$ Hence, our findings should be considered as part of discourse on the repurposing potential of TNF inhibitors for PD prevention and treatment, particularly if selective inhibitors of TNF-TNFR1 signaling become available. Future Mendelian randomization studies could use large-scale GWAS of PD progression to help evaluate the disease-modifying potential of selective TNFR1 inhibitors for PD treatment.

\section{Acknowledgment}

The authors thank the participants from all cohorts who contributed to this study; Dr. Yiqiang Zhan from the German Center for Neurodegenerative Diseases and Dr. Yunzhang Wang from Karolinska Institutet for suggestions on analytical packages and/or platforms during the data preprocessing stage; and members of the CHARGE Inflammation Working Group, the IPDGC, and 23andMe for granting access to GWAS summary statistics for CRP and PD traits. Contributors to the IPDGC are listed at pdgenetics.org/partners. Contributors in the 23andMe Research Team are Michelle Agee, Adam Auton, Robert K. Bell, Katarzyna Bryc, Paul Cannon, Sarah L. Elson, Pierre Fontanillas, Nicholas A. Furlotte, Karl Heilbron, Barry Hicks, David Hinds, Karen E. Huber, Ethan M. Jewett, Yunxuan Jiang, Aaron Kleinman, Keng-Han Lin, Nadia K. Litterman, Jennifer C. McCreight, Matthew H. McIntyre, Kimberly F. McManus, Joanna L. Mountain, Elizabeth S. Noblin, Carrie A.M. Northover, 
Steven J. Pitts, G. David Poznik, J. Fah Sathirapongsasuti, Janie F. Shelton, Suyash Shringarpure, Chao Tian, Joyce Y. Tung, Vladimir Vacic, and Xin Wang.

\section{Study Funding}

Study funded by the Swedish Research Council (grant 201702175). Dylan M. Williams is funded by the United Kingdom's Medical Research Council (MC_UU_00019/2).

\section{Disclosure}

X. Kang, A. Ploner, N.L. Pedersen, and S. Bandres-Ciga report no disclosures. A.J. Noyce works at the Preventive Neurology Unit, which is funded by the Barts Charity; holds grants from the Aligning Science Across Parkinson's Initiative and Parkinson's UK; and received personal fees from Profile, Roche, Biogen, Bial, AbbVie, and Britannia, outside the submitted work. K. Wirdefeldt and D.M. Williams reports no disclosures. Go to Neurology.org/N for full disclosures.

\section{Publication History}

Received by Neurology June 10, 2020. Accepted in final form December 11, 2020.

\section{Appendix Authors}

\begin{tabular}{|c|c|c|}
\hline Name & Location & Contribution \\
\hline $\begin{array}{l}\text { Xiaoying } \\
\text { Kang, MSc, } \\
\text { MPH }\end{array}$ & $\begin{array}{l}\text { Karolinska Institutet, } \\
\text { Stockholm, Sweden }\end{array}$ & $\begin{array}{l}\text { Supporting study design } \\
\text { and conceptualization, } \\
\text { performing data analysis, } \\
\text { and drafting manuscript }\end{array}$ \\
\hline $\begin{array}{l}\text { Alexander } \\
\text { Ploner, PhD }\end{array}$ & $\begin{array}{l}\text { Karolinska Institutet, } \\
\text { Stockholm, Sweden }\end{array}$ & Revising manuscript \\
\hline $\begin{array}{l}\text { Nancy L. } \\
\text { Pedersen, } \\
\text { PhD }\end{array}$ & $\begin{array}{l}\text { Karolinska Institutet, } \\
\text { Stockholm, Sweden }\end{array}$ & Revising manuscript \\
\hline $\begin{array}{l}\text { Sara } \\
\text { Bandres- } \\
\text { Ciga, PhD }\end{array}$ & $\begin{array}{l}\text { National Institute on Aging, } \\
\text { Bethesda, MD; Instituto de } \\
\text { Investigación Biosanitaria } \\
\text { de Granada, Spain }\end{array}$ & $\begin{array}{l}\text { Supporting data analysis, } \\
\text { and revising manuscript }\end{array}$ \\
\hline $\begin{array}{l}\text { Alastair J. } \\
\text { Noyce, } \\
\text { MRCP, PhD }\end{array}$ & $\begin{array}{l}\text { Queen Mary University of } \\
\text { London; UCL Institute of } \\
\text { Neurology, London, UK }\end{array}$ & Revising manuscript \\
\hline $\begin{array}{l}\text { Karin } \\
\text { Wirdefeldt, } \\
\text { MD, PhD }\end{array}$ & $\begin{array}{l}\text { Karolinska Institutet, } \\
\text { Stockholm, Sweden }\end{array}$ & $\begin{array}{l}\text { Supporting study design } \\
\text { and conceptualization, and } \\
\text { revising manuscript }\end{array}$ \\
\hline $\begin{array}{l}\text { Dylan M. } \\
\text { Williams, } \\
\text { PhD }\end{array}$ & $\begin{array}{l}\text { Karolinska Institutet, } \\
\text { Stockholm, Sweden; } \\
\text { University College London, } \\
\text { UK }\end{array}$ & $\begin{array}{l}\text { Leading study design and } \\
\text { conceptualization, } \\
\text { supporting data analysis } \\
\text { and revising manuscript }\end{array}$ \\
\hline
\end{tabular}

\section{References}

1. Houser MC, Tansey MG. The gut-brain axis: is intestinal inflammation a silent driver of Parkinson's disease pathogenesis? NPJ Parkinsons Dis 2017;3:3.

2. McCoy MK, Tansey MG. TNF signaling inhibition in the CNS: implications for normal brain function and neurodegenerative disease. J Neuroinflammation 2008 ; 45 .

3. Neurath MF. Current and emerging therapeutic targets for IBD. Nat Rev Gastroenterol Hepatol 2017;14:269-278.

4. Peter I, Dubinsky M, Bressman S, et al. Anti-tumor necrosis factor therapy and incidence of Parkinson disease among patients with inflammatory bowel disease. JAMA Neurol 2018;75:939-946.
5. Walker VM, Davey Smith G, Davies NM, Martin RM. Mendelian randomization: a novel approach for the prediction of adverse drug events and drug repurposing opportunities. Int J Epidemiol 2017;46:2078-2089.

6. Swerdlow DI, Kuchenbaecker KB, Shah S, et al. Selecting instruments for mendelian randomization in the wake of genome-wide association studies. Int J Epidemiol 2016;45:1600-1616.

7. Lawlor DA, Harbord RM, Sterne JA, Timpson N, Davey Smith G. Mendelian randomization: using genes as instruments for making causal inferences in epidemiology. Stat Med 2008;27:1133-1163.

8. Burgess S, Scott RA, Timpson NJ, Davey Smith G, Thompson SG; EPIC-InterAct Consortium. Using published data in mendelian randomization: a blueprint for efficient identification of causal risk factors. Eur J Epidemiol 2015;30:543-552.

9. Ligthart S, Vaez A, Võsa U, et al. Genome analyses of $>200,000$ individuals identify 58 loci for chronic inflammation and highlight pathways that link inflammation and complex disorders. Am J Hum Genet 2018;103:691-706.

10. Astle WJ, Elding H, Jiang T, et al. The allelic landscape of human blood cell trait variation and links to common complex disease. Cell 2016;167:1415-1429.e1419.

11. Nalls MA, Blauwendraat C, Vallerga CL, et al. Identification of novel risk loci, causal insights, and heritable risk for Parkinson's disease: a meta-analysis of genome-wide association studies. Lancet Neurol 2019;18:1091-1102.

12. Blauwendraat $\mathrm{C}$, Heilbron $\mathrm{K}$, Vallerga $\mathrm{CL}$, et al. Parkinson's disease age at onset genome-wide association study: defining heritability, genetic loci, and $\alpha$-synuclein mechanisms. Mov Disord 2019;34:866-875.

13. Ortí-Casañ N, Wu Y, Naudé PJW, De Deyn PP, Zuhorn IS, Eisel ULM. Targeting TNFR2 as a novel therapeutic strategy for Alzheimer's disease. Front Neurosci 2019;13:49.

14. Pegoretti V, Baron W, Laman JD, Eisel ULM. Selective modulation of TNF-TNFRs signaling: insights for multiple sclerosis treatment. Front Immunol 2018;9:925.

15. Fischer R, Kontermann RE, Pfizenmaier K. Selective targeting of TNF receptors as a novel therapeutic approach. Front Cell Dev Biol 2020;8:401.

16. Steeland S, Libert C, Vandenbroucke RE. A new venue of TNF targeting. Int J Mol Sci 2018;19:1442.

17. Khanna R, Narula N, Feagan BG. The role of biomarkers in clinical trials of inflammatory bowel disease. Inflamm Bowel Dis 2018;24:1619-1623.

18. Ahola-Olli AV, Würtz P, Havulinna AS, et al. Genome-wide association study identifies 27 loci influencing concentrations of circulating cytokines and growth factors. Am J Hum Genet 2017;100:40-50.

19. Burgess S, Davies NM, Thompson SG. Bias due to participant overlap in two-sample mendelian randomization. Genet Epidemiol 2016;40:597-608.

20. Cohen BL, Sachar DB. Update on anti-tumor necrosis factor agents and other new drugs for inflammatory bowel disease. BMJ 2017;357:j2505.

21. Antonazzo IC, Raschi E, Forcesi E, et al. Multiple sclerosis as an adverse drug reaction: clues from the FDA Adverse Event Reporting System. Expert Opin Drug Saf 2018;17:869-874.

22. Freeman HJ, Flak B. Demyelination-like syndrome in Crohn's disease after infliximab therapy. Can J Gastroenterol 2005;19:313-316.

23. Sicotte NL, Voskuhl RR. Onset of multiple sclerosis associated with anti-TNF therapy. Neurology 2001;57:1885-1888.

24. Tanno M, Nakamura I, Kobayashi S, Kurihara K, Ito K. New-onset demyelination induced by infliximab therapy in two rheumatoid arthritis patients. Clin Rheumatol 2006;25:929-933.

25. The Lenercept Multiple Sclerosis Study Group and the University of British Columbia MS/MRI Analysis Group. TNF neutralization in MS: results of a randomized, placebo-controlled multicenter study.Neurology 1999;53:457-465.

26. van Oosten BW, Barkhof F, Truyen L, et al. Increased MRI activity and immune activation in two multiple sclerosis patients treated with the monoclonal anti-tumor necrosis factor antibody cA2. Neurology 1996;47:1531-1534.

27. de Lange KM, Moutsianas L, Lee JC, et al. Genome-wide association study implicates immune activation of multiple integrin genes in inflammatory bowel disease. Nat Genet 2017;49:256-261.

28. Beecham AH, Patsopoulos NA, Xifara DK, et al. Analysis of immune-related loci identifies 48 new susceptibility variants for multiple sclerosis. Nat Genet 2013;45:1353-1360.

29. Burgess S, Thompson SG; CRP CHD Genetics Collaboration. Avoiding bias from weak instruments in mendelian randomization studies. Int J Epidemiol 2011;40:755-764.

30. Burgess S, Zuber V, Valdes-Marquez E, Sun BB, Hopewell JC. Mendelian randomization with fine-mapped genetic data: choosing from large numbers of correlated instrumental variables. Genet Epidemiol 2017;41:714-725.

31. Hemani G, Zheng J, Elsworth B, et al. The MR-Base platform supports systematic causal inference across the human phenome. Elife 2018;7:e34408.

32. Gregory AP, Dendrou CA, Attfield KE, et al. TNF receptor 1 genetic risk mirrors outcome of anti-TNF therapy in multiple sclerosis. Nature 2012;488:508-511.

33. Cole TJ, Altman DG. Statistics Notes: percentage differences, symmetry, and natural logarithms. BMJ 2017;358:j3683.

34. Yavorska OO, Burgess S. mendelianRandomization: an R package for performing mendelian randomization analyses using summarized data. Int J Epidemiol 2017;46:1734-1739.

35. University of Cambridge CEU. Haematological Trait GWAS Summary Statistics [online]. Available at: bloodcellgenetics.org/. Accessed November 11, 2019.

36. Mitoma $\mathrm{H}$, Horiuchi $\mathrm{T}$, Tsukamoto $\mathrm{H}$, Ueda N. Molecular mechanisms of action of anti-TNF- $\alpha$ agents: comparison among therapeutic TNF- $\alpha$ antagonists. Cytokine 2018;101:56-63.

37. McCoy MK, Martinez TN, Ruhn KA, et al. Blocking soluble tumor necrosis factor signaling with dominant-negative tumor necrosis factor inhibitor attenuates loss of dopaminergic neurons in models of Parkinson's disease. J Neurosci 2006;26:9365-9375.

38. Burgess S, Small DS, Thompson SG. A review of instrumental variable estimators for mendelian randomization. Stat Methods Med Res 2017;26:2333-2355.

39. Nelson MR, Tipney H, Painter JL, et al. The support of human genetic evidence for approved drug indications. Nat Genet 2015;47:856-860. 


\section{Neurology}

\section{Tumor Necrosis Factor Inhibition and Parkinson Disease: A Mendelian Randomization Study \\ Xiaoying Kang, Alexander Ploner, Nancy L. Pedersen, et al.}

Neurology 2021;96;e1672-e1679 Published Online before print February 19, 2021

DOI 10.1212/WNL.0000000000011630

This information is current as of February 19, 2021

Updated Information \& Services

References

Subspecialty Collections

Permissions \& Licensing

Reprints including high resolution figures, can be found at: http://n.neurology.org/content/96/12/e1672.full

This article cites 38 articles, 6 of which you can access for free at: http://n.neurology.org/content/96/12/e1672.full\#ref-list-1

This article, along with others on similar topics, appears in the following collection(s):

All CBMRT/Null Hypothesis

http://n.neurology.org/cgi/collection/all_cbmrt_null_hypothesis All epidemiology

http://n.neurology.org/cgi/collection/all_epidemiology

Association studies in genetics

http://n.neurology.org/cgi/collection/association_studies_in_genetics Parkinson's disease/Parkinsonism

http://n.neurology.org/cgi/collection/parkinsons_disease_parkinsonism

Information about reproducing this article in parts (figures,tables) or in its entirety can be found online at:

http://www.neurology.org/about/about_the_journal\#permissions

Information about ordering reprints can be found online:

http://n.neurology.org/subscribers/advertise

Neurology ${ }^{\circledR}$ is the official journal of the American Academy of Neurology. Published continuously since 1951, it is now a weekly with 48 issues per year. Copyright Copyright ( 2021 The Author(s). Published by Wolters Kluwer Health, Inc. on behalf of the American Academy of Neurology.. All rights reserved. Print ISSN: 0028-3878. Online ISSN: 1526-632X.

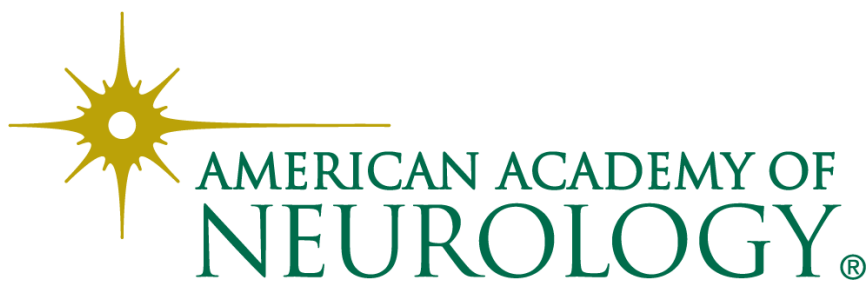

